\title{
Reflexões acerca do ensino de Matemática Discreta no curso de Ciência da Computação
}

\author{
Lindinês C. da Silva Djair P. dos Santos \\ Fernando V. Costa Júnior Elthon A. da S. Oliveira \\ Universidade Federal de Alagoas, UFAL \\ 57309-005, Arapiraca, AL \\ E-mail: lindinescoleta@hotmail.com, djairpsc@hotmail.com, \\ fernando.math@hotmail.com, elthon@arapiraca.ufal.br.
}

\section{RESUMO}

Os alunos do curso de Ciência da Computação da Universidade Federal de Alagoas (UFAL) enfrentam problemas de rendimento relacionados às disciplinas matemáticas, como os Cálculos $1 \mathrm{e} 2$, Matemática Discreta e Álgebra Linear. Nesta perspectiva, percebemos a necessidade de investigar e buscar compreender o problema, a fim de encontrar soluções que possibilitem a melhora deste quadro.

Como estratégia de investigação do caso, realizamos uma pesquisa com 78 alunos, do primeiro ao oitavo período do curso de Ciência da Computação, através de um formulário online. A maior parte do questionário foi composta por perguntas com escala de 0 a 10, acrescido de algumas perguntas de múltipla escolha e de uma pergunta aberta (Cf. [1]). Constatamos que, apesar de $75 \%$ dos alunos afirmarem que reconhecem a importância da matemática para a Ciência da Computação (nota 7-10), o aproveitamento geral nas disciplinas, de acordo com dados obtidos de professores (Cf. [3]), aponta para um baixo rendimento dos alunos. Um exemplo disto é a disciplina de Matemática Discreta, foco deste trabalho ${ }^{1}$, que em 2012.2 apresentou uma média de notas de 4.76, sendo a nota mínima para aprovação 7.00. Em 2013.2, com duas turmas da mesma disciplina, as médias gerais do primeiro bimestre são ainda mais baixas, 3.79 numa turma e 3.31 em outra.

Diante desta realidade, questionamo-nos a respeito do que parece uma inconsistência nas respostas obtidas na pesquisa. Por que, apesar da maioria dos alunos reconhecer a importância e se interessar em aprender Matemática, o rendimento ainda é tão baixo? Elaboramos uma hipótese em torno dos possíveis motivos de tal problema: pensamos que os alunos se dedicam às disciplinas específicas de seu curso ao ponto de não reservarem tempo de estudo suficiente, ou de não se empenharem o bastante, às disciplinas matemáticas para conseguir um bom aproveitamento. Aliado a isso, supomos que, na concepção dos alunos, há uma divisão das disciplinas em específicas e não específicas, mesmo que oficialmente não haja essa divisão. Esta concepção pode causar um afastamento do interesse dos alunos pelo estudo destas disciplinas. "Não específico" torna-se sinônimo de "não interessante", ou, para alguns, "não importante".

Essa hipótese ajuda a entender, por exemplo, o problema supradito. É objetivo do trabalho mostrar como a disciplina de Matemática Discreta pode ser abordada explicitamente como pertencente ao corpo de disciplinas específicas. A elaboração e aplicação de intervenções podem contribuir para a aderência da concepção que julgamos correta.

Intervenções estas que consistam em exibir exemplos de aparatos/mecanismos computacionais que se utilizem de arcabouços matemáticos, e que busquem também mostrar como as teorias matemáticas estudadas no curso são a base da construção computacional dos aparatos/mecanismos expostos. A ideia consiste em evidenciar a importância e buscar o interesse dos alunos pelas disciplinas matemáticas, exemplificando aplicações das teorias matemáticas à Ciência da Computação. Para tanto, serão construídos

${ }^{1}$ Este trabalho faz parte de um projeto de intervenção que busca abarcar todas as disciplinas matemáticas do curso. 
mecanismos em forma de material de divulgação de aplicações que possibilitem o aluno associar, por si mesmo, estas duas áreas.

Como exemplo de relação, procuraremos exibir como a Matemática Discreta fundamenta várias das formas de criptografar dados, a partir da Congruência Modular, como a Criptografia RSA, que envolve um par de chaves: uma pública e uma privada. Toda mensagem cifrada usando uma chave pública só pode ser decifrada usando a respectiva chave privada. Para tanto, escolhe-se dois números primos gigantescos, $p$ e $q$, preferencialmente com mais de cem dígitos, e define-se $M=p \cdot q$. Cada pessoa que utiliza o sistema escolhe um $k \in \mathbb{N}$, tal que $m d c(k, \phi(M))=1$, onde $\phi$ é a Função $\phi$ de Euler, e então obtém-se a chave pública, que será $(M, k)$, usada da seguinte forma:

$$
(\text { texto codificado }) \equiv(\text { texto original })^{k}(\bmod M) \text {. }
$$

Para obter a chave privada $(M, t)$, que decodificará a mensagem, é necessário resolver a seguinte congruência:

$$
k \cdot t \equiv 1(\bmod \phi(M)) .
$$

Tal chave é usada da seguinte maneira:

$$
(\text { texto original }) \equiv(\text { texto codificado })^{t}(\bmod M)
$$

Temos, ainda, a Criptografia por Curvas Elípticas, que se utiliza do conteúdo aprendido em Geometria Analítica e Álgebra Linear. Essa prática pode enriquecer a concepção acerca destas disciplinas ao ponto de fazer com que sejam vistas, não como separadas, mas como diretamente ligadas, pertencentes de fato, ao corpo de disciplinas específicas da grade curricular do curso de Ciência da Computação. Essa ideia pode ser generalizada para as demais disciplinas matemáticas do curso, as quais podem ser abordadas contextualizadas com a área computacional. Isso pode ser realizado ao buscar a contextualização das disciplinas matemáticas com o curso, em termos de aplicação ou fundamentação de disciplinas que se sucederão. Ressaltamos que essa prática deve se prolongar durante todo o curso, com enfoque nos primeiros períodos, onde serão formadas as primeiras concepções acerca da Matemática na Ciência da Computação.

Supondo a veracidade da hipótese, acreditamos ser necessário modificar a concepção antes ressaltada, decorrente dos problemas antes levantados. Isto é, ao que tudo parece, a suposta divisão, feita internamente pelos alunos, de algumas das disciplinas matemáticas, essenciais ao desenvolvimento do curso, como não específicas, se mostra como um empecilho para a dedicação dos alunos ao seu estudo. Buscando quebrar o bloqueio que supomos existir, criado por eles, e surgido a partir da concepção errônea da posição que a Matemática tem em relação ao seu curso, a proposta de intervir na educação do alunos, procurando contextualizar a disciplina de Matemática Discreta com as demais disciplinas específicas do curso, pode contribuir para a aprendizagem dos alunos de Ciência da Computação.

Palavras-chave: Ensino, Matemática, Ciência da Computação.

\section{Referências}

[1] F.V. Costa Júnior, "Ensino de Matemática no curso de Ciência da Computação da Universidade Federal de Alagoas - Campus Arapiraca", disponível em: http://logicaematematica.wordpress.com/2014/02/22/pesquisa-cdac/.

[2] V.B.S. Flose, “Criptografia e Curvas Elípticas”, Dissertação de Mestrado, IGCE-Unesp, 2011.

[3] E.A.S. Oliveira, "Ensino de Matemática no curso de Ciência da Computação", UFAL, 2013, entrevista concedida a Fernando Vieira Costa Júnior.

[4] M.C. Oliveira, "Aritmética: criptografia e outras aplicações de congruências", Dissertação de Mestrado, CCET-UFMS, 2013. 